\title{
The Effect of Femoral Stem Length on Inpatient Rehabilitation Outcomes
}

\author{
Serkan BAKIRHAN ${ }^{1}$, Bayram UNVER ${ }^{2, *}$, Vasfi KARATOSUN ${ }^{3}$ \\ ${ }^{1}$ Department of Physiotherapy and Rehabilitation, School of Health, Izmir University, Izmir, Turkey \\ ${ }^{2}$ School of Physiotherapy, Dokuz Eylül University, Izmir, Turkey \\ ${ }^{3}$ Department of Orthopaedics, School of Medicine, Dokuz Eylül University, Izmir, Turkey \\ *Corresponding author: bayram.unver@deu.edu.tr
}

Received January 08, 2013; Revised February 04, 2013; Accepted February 16, 2013

\begin{abstract}
Thrust plate prosthesis (TPP) has load-transferring characteristics different from those of conventional intramedullary stemmed prostheses (ISP). We investigate whether prosthesis type (intramedullary or extramedullary application) can improve early functional activities in hospital patients with hip arthroplasty. Early postoperative functional activities of 30 patients with TPP were compared with 31 patients treated by ISP. Each group received same rehabilitation programmes: TPP patients with early full weight bearing and ISP patients with early full weight bearing. Patients were evaluated postoperatively (on the second, sixth and discharge days). Their functional activities were assessed with Iowa Level of Assistance Scale (ILAS), walking speed with Iowa Ambulation Velocity Scale (IAVS), hip functions with Harris Hip Scoring System, and hip motions with goniometer. TPP patients achieved higher scores for total functional activities on the second and sixth postoperative days and during discharge than did ISP patients $(\mathrm{p}<0.05)$. Comparison of the walking speed of the patients on the second and sixth postoperative days and during discharge showed that TPP patients walked faster than did ISP patients $(\mathrm{p}<0.05)$. TPP patients had higher Harris hip scores and a higher hip motion degree than did ISP patients during discharge $(\mathrm{p}<0.05)$. We conclude that patients with TPP gain their independence in functional activities earlier than do patients with ISP.
\end{abstract}

Keywords: Thrust plate prosthesis, Intramedullary stemmed prostheses, Hip, Joint, Osteoarthritis, Replacement, Rehabilitation

\section{Introduction}

The ultimate goal of rehabilitation after total hip prosthesis (THP) is to maximize functional performance and to improve an individual's ability in order to perform daily activities earlier and in a shorter hospital stay [1]. Total joint replacement patients represent a major proportion of patients treated with physical therapy in acute care institutions, and there is some consensus among physical therapists about the ideal treatment or assessment of these patients $[2,3]$. Survey data indicated that sit-tostand, supine-to-sit, ambulation, stair climbing and ambulation velocity were the criteria used for discharging THP patients from physical therapy $[2,4]$.

Information about short-term recovery is needed in order to inform patients about expected rates of progress, and to help clinicians to assess patients for accurate planning of hospital resources. This information helps medical and physical therapy staff to give more accurate recovery expectations to patients undergoing arthroplasties [5,6,7]. Post-operative rehabilitation for THP continues to be the subject of research, with efforts being made to reduce associated costs whilst maintaining and improving the quality of clinical care. In order to assess the clinical effects of arthroplasty rehabilitation treatment, measurement of activity is essential. Preoperative diagnosis and functional level, delayed surgery, comorbidities, level of mobility, use of assistive device, physiotherapy training the duration of the onset of the treatment affect hospital stay process and functional results [8].

Several surgical factors have been recognised as affecting hospital length of stay. These factors include type of incision, length of incision, anaesthetic technique, and the use of short or long stem femoral components $[9,10]$. The recent use of short stem femoral components in THP may theoretically decreases bone and soft tissue damage and limit blood loss, enabling earlier mobilization, faster recovery and decreasing hospital length of stay [9].

The thrust plate prosthesis (TPP) is a neck-sparing hip prosthesis with cementless fixation in the metaphysis of the proximal femur. The principle of the TPP is to transfer the resulting forces from the hip joint via a thrust plate directly to the femoral neck and most importantly to the cortical bone of the calcar. Clinical and experimental studies have shown that TPP produces relatively more physiological distribution of the proximal femoral strain, thus allowing early mobility $[4,11,12,13]$. Due to differences in biomechanical load transfer, TPP applications allow early mobilization and weight bearing. In several studies, it has been indicated that performing weight bearing at an early stage accelerated rehabilitation and had no negative effect on the fixation of the prosthesis $[1,4]$.

Careful review of the literature revealed no study concerning the effects femoral stem types on early functional activities outcomes following hip arthroplasty. 
For this reason, we compared the relationship between independence levels in functional activities in the early postoperative period in patients with different femoral stem type's application.

\section{Materials and Methods}

\subsection{Participants}

In our study, we retrospectively scanned patients' records and investigated in-hospital functional activity outcomes of the patients who underwent TPP and conventional THP due to coxarthrosis. The study included 61 patients (16 men and 45 women) with primary hip arthroplasty [TPP and conventional THP] performed by the same surgeon (VK) using the Hardinge anterolateral approach.

Thirty-three hips (3 bilateral) of 30 patients were treated by TPP. The right side was affected in 15 cases, the left side in 12 cases. Thirty-two hips ( 1 bilateral) of 31 patients were treated by conventional THP. The right side was affected in 16 cases, the left side in 14 cases. The demographic data and the type of hip replacement are tabulated in Table 1. The exclusion criteria were: (a) arthritis in other joints necessitating treatment, (b) neurological or medical conditions causing locomotor disability, and (c) revision of hip prosthesis.

\begin{tabular}{cccc}
\multicolumn{4}{c}{ Table 1. Baseline characteristics of study patients } \\
\hline \\
TPP & ISP & $\mathrm{p}$ \\
& $\mathrm{X} \pm \mathrm{SD}$ & $\mathrm{X} \pm \mathrm{SD}$ & \\
\hline Age (years) & $60.06 \pm 9.82$ & $64.54 \pm 12.21$ & 0.120 \\
Height $(\mathrm{cm})$ & $163.60 \pm 8.78$ & $162.61 \pm 7.73$ & 0.643 \\
Weight $(\mathrm{kg})$ & $71.66 \pm 8.87$ & $69.25 \pm 13.16$ & 0.407 \\
Body mass index & $26.93 \pm 4.01$ & $26.17 \pm 4.57$ & 0.496 \\
$\left(\mathrm{~kg} / \mathrm{m}^{2}\right)$ & & & \\
\hline
\end{tabular}

Values are expressed as means \pm SD

\subsection{Procedure}

Thirty-one consecutive patients underwent primary uncemented conventional THP (Secur-Fit Plus, Stryker Orthopaedics, Mahwah, NJ) and thirty consecutive patients underwent primary uncemented TPP. The femoral component was a third-generation TPP (Allopro, Sulzer Medica, Winterthur, Switzerland) in all patients. TPP was implanted without cement to the metaphysis of the proximal femur, and was secured to the lateral cortex of the femur with a plate and screws.

Table 2. Details of the rehabilitation programme

\begin{tabular}{lc}
\hline & Postoperative \\
\hline Deep breathing, cough & day 1 \\
Calf exercise & day 1 \\
Isometric quadriceps and gluteal sets & day 1 \\
Strengthening exercises to unaffected extremities & day 1 \\
and trunk muscles & day 1 \\
Hip precautions & day 1 \\
Full weight bearing & day 2 \\
Passive, assisted range-of-motion exercises & day 2 \\
Transfers to unaffected side & day 2 \\
Out of bed, stand or walking with walker & day 3 \\
Transfers (bed to chair, toilet) & day 3 \\
Use appropriate dressing and toileting equipment & $3-7$ days \\
Walking with crutches & 5-7 days \\
Stair training &
\end{tabular}

All patients received standard post-operative treatment from a physiotherapist. Patients were informed on the surgical procedure and postoperative physiotherapy program prior to the operation. The details of the rehabilitation protocols are displayed in Table 2. All these interventions were provided by physical therapists in the study (SB). The postoperative rehabilitation of the patients was initiated the day after surgery and repeated twice a day [1].

\subsection{Outcome Measures}

Functional activities of the all patients were evaluated postoperatively by a blinded observer who had fourteen years of experience in physical therapy with the Iowa Level of Assistance Scale (ILAS). The four functionally related activities assessed were ability to move into a sitting position from supine lying, to stand from sitting position, to ambulate $15 \mathrm{feet}$; and to climb up and down three steps. The Iowa Ambulation Velocity Scale (IAVS), which is an ordinal ambulation velocity scale graded from 0 to 6 , was used (Table 3 and Table 4). The total functional score represented the sum of the level of assistance values for all four functionally related activities [2]. Walking speed of the patients was assessed with the IAVS. The patients were assessed with the ILAS and IAVS respectively, on the second and sixth postoperative days and during discharge [2]. In addition, hip range of motion and Harris hip score were measured [14].

Table 3. Definitions of grades in the Iowa Ambulation Velocity Scale
\begin{tabular}{|l|l|}
\hline Grade & Definition \\
\hline 0: Not tested & $\begin{array}{l}\text { A patient who is not tested for reasons of } \\
\text { safety, determined by the therapist's } \\
\text { judgement }\end{array}$ \\
\hline $\begin{array}{l}\text { 1: Failed maximal } \\
\text { assistance }\end{array}$ & $\begin{array}{l}\text { An activity that is attempted but is not } \\
\text { completed, even with maximal assistance }\end{array}$ \\
\hline $\begin{array}{l}\text { 2: Maximal } \\
\text { assistance }\end{array}$ & $\begin{array}{l}\text { The therapist provides a total of three or } \\
\text { more points of contact with the patient }\end{array}$ \\
\hline $\begin{array}{l}\text { 3: Moderate } \\
\text { assistance }\end{array}$ & $\begin{array}{l}\text { The therapist provides two points of contact } \\
\text { with the patient }\end{array}$ \\
\hline $\begin{array}{l}\text { 4: Minimal } \\
\text { assistance }\end{array}$ & $\begin{array}{l}\text { The therapist provides one point of contact } \\
\text { with the patient }\end{array}$ \\
\hline $\begin{array}{l}\text { 5: Standby } \\
\text { assistance }\end{array}$ & $\begin{array}{l}\text { The therapist would not feel comfortable } \\
\text { leaving the patient; the therapist, however, } \\
\text { provides no physical assistance }\end{array}$ \\
\hline 6: Independent & $\begin{array}{l}\text { The therapist could leave the room and the } \\
\text { patient could safely perform the activity } \\
\text { being assessed }\end{array}$ \\
\hline
\end{tabular}

Table 4. The Iowa Ambulation Velocity Scale

\begin{tabular}{|c|c|}
\hline $\begin{array}{c}\text { Time taken to ambulate 13.4 metres (44 feet) } \\
\text { (seconds) }\end{array}$ & Grade \\
\hline$\leq 20$ & 0 \\
\hline $21-30$ & 1 \\
\hline $31-40$ & 2 \\
\hline $41-50$ & 3 \\
\hline $51-60$ & 4 \\
\hline $61-70$ & 5 \\
\hline$>70$ & 6 \\
\hline
\end{tabular}

\subsection{Statistical Analysis}

Statistical analyses were performed using Statistical Package for the Social Sciences for Windows (Version 15.0, SPSS Inc., Chicago, IL, USA). Mann-Whitney Utest was used to evaluate group differences (age, weight, height, BMI, Iowa Level of Assistance Scale, Iowa Ambulation Velocity Scale, Harris hip score, range-ofmotion) where appropriate. P-values less than 0.05 were accepted as significant.

\section{Results}


There were no significant differences between the groups when compared with the parameters listed in the demographic data (Table 1).

All patients in both groups were evaluated on the second and sixth postoperative days and during discharge from the hospital. However, TPP patients had higher total
ILAS scores than did the conventional THP patients $(p<0.05)$ (Table 5). Comparison of the IAVS scores of the patients on the second and sixth postoperative days and during discharge showed that TPP patients walked faster than conventional THP patients did $(\mathrm{p}<0.05)$ (Table 5).

Table 5. Comparison of the postoperative second, sixth days and discharge patients with TPP and ISP in terms of ILAS and IAVS score

\begin{tabular}{|c|c|c|c|c|c|c|c|c|c|}
\hline \multirow[b]{2}{*}{ ILAS } & \multicolumn{3}{|c|}{ TPP } & \multicolumn{3}{|c|}{ ISP } & \multirow[b]{2}{*}{$\mathrm{p}$} & \multirow[b]{2}{*}{$\mathrm{p}^{1}$} & \multirow[b]{2}{*}{$\mathrm{p}^{2}$} \\
\hline & $\begin{array}{c}\text { Second } \\
\text { days } \\
\mathrm{X} \pm \mathrm{SD}\end{array}$ & $\begin{array}{c}\text { Sixth days } \\
\mathrm{X} \pm \mathrm{SD}\end{array}$ & $\begin{array}{c}\text { Discharge } \\
\mathrm{X} \pm \mathrm{SD}\end{array}$ & $\begin{array}{c}\text { Second } \\
\text { days } \\
\mathrm{X} \pm \mathrm{SD}\end{array}$ & $\begin{array}{l}\text { Sixth days } \\
\mathrm{X} \pm \mathrm{SD}\end{array}$ & $\begin{array}{c}\text { Discharge } \\
\mathrm{X} \pm \mathrm{SD}\end{array}$ & & & \\
\hline Supine-to-sit & $2.70 \pm 0.53$ & $3.80 \pm 0.84$ & $4.76 \pm 1.04$ & $2.29 \pm 0.64$ & $3.03 \pm 0.91$ & $3.77 \pm 0.92$ & 0.009 & 0.001 & 0.000 \\
\hline Sit-to-stand & $2.73 \pm 0.58$ & $3.46 \pm 0.93$ & $4.60 \pm 1.03$ & $2.25 \pm 0.63$ & $2.83 \pm 0.93$ & $3.41 \pm 0.80$ & 0.003 & 0.011 & 0.000 \\
\hline Ambulate 15 feet & $2.63 \pm 0.71$ & $3.36 \pm 1.03$ & $4.50 \pm 1.13$ & $2.32 \pm 0.79$ & $2.96 \pm 0.94$ & $3.40 \pm 0.70$ & 0.114 & 0.121 & 0.000 \\
\hline Climb up and down three steps & - & $2.63 \pm 0.58$ & $2.86 \pm 0.81$ & - & $2.33 \pm 0.48$ & $2.60 \pm 0.68$ & - & 0.071 & 0.198 \\
\hline Total function score & $8.06 \pm 1.57$ & $12.56 \pm 2.93$ & $16.73 \pm 3.27$ & $6.87 \pm 1.91$ & $10.41 \pm 3.57$ & $12.96 \pm 3.11$ & 0.011 & 0.013 & 0.000 \\
\hline \multicolumn{10}{|l|}{ IAVS } \\
\hline Walking speed & $5.50 \pm 0.68$ & $4.63 \pm 0.71$ & $4.03 \pm 0.85$ & $5.87 \pm 0.34$ & $5.35 \pm 0.66$ & $4.83 \pm 0.82$ & 0.009 & 0.000 & 0.000 \\
\hline
\end{tabular}

TPP: Thrust plate prosthesis, ISP : Intramedullary stemmed prostheses

ILAS: Iowa Level of Assistance Scale, IAVS: Iowa Ambulation Velocity Scale

p: Comparison of the postoperative second day patients with TPP and ISP in terms of ILAS and IAVS score.

$\mathbf{p}^{\mathbf{1}}$ : Comparison of the postoperative sixth day patients with TPP and ISP in terms of ILAS and IAVS score.

$\mathbf{p}^{2}$ : Comparison of the patients with TPP and ISP in terms of ILAS and IAVS score during discharge.

Values are expressed as means \pm SD

When the groups were compared as they were, TPP patients had significantly greater Harris hip scores and higher hip motion degrees than conventional THP patients during discharge $(\mathrm{p}<0.05)$ (Table 6). No complications of the hip were observed in the TPP and conventional THP patients after surgery.

Table 6. Comparison of length of hospital stay, range of motion and Harris hip score of patients with TPP and ISP during discharge

\begin{tabular}{cccc}
\multicolumn{3}{c}{ Harris hip score of patients with TPP and ISP during discharge } \\
\hline & TPP & ISP & $\mathrm{p}$ \\
& $\mathrm{X} \pm \mathrm{SD}$ & $\mathrm{X} \pm \mathrm{SD}$ & \\
\hline Hip flexion $\left(^{\circ}\right)$ & $57.16 \pm 12.6$ & $45.45 \pm 12.4$ & $\mathbf{0 . 0 0 1 *}$ \\
& 0 & 1 & \\
Hip abduction $\left(^{\circ}\right)$ & $31.70 \pm 7.81$ & $23.48 \pm 8.55$ & $\mathbf{0 . 0 0 0 *}$ \\
Harris hip Score & $52.60 \pm 8.18$ & $45.41 \pm 8.90$ & $\mathbf{0 . 0 0 2} *$ \\
Length of hospital stay & $9.26 \pm 3.07$ & $8.16 \pm 2.01$ & $\mathbf{0 . 1 0 1}$ \\
(day) & & & \\
\hline
\end{tabular}

Values are expressed as means \pm SD

$* \mathrm{p}<0.05$

\section{Discussion}

Many factors affect the rehabilitation results following the application of total hip replacement. In several studies, it has been indicated that functional recovery is slower and develops later in the following: patients with poor general health status, females, obese patients, those living alone, the elderly (over 65 years of age), those who undergo conventional THP after fracture compared with those who undergo elective THP, those who undergo revision THP compared to those who undergo primary conventional THP, those who undergo cementless conventional THP compared to those who undergo hybrid or cemented conventional THP, those with an accompanying disease, those who have not had pre-operative physiotherapy and those who start post-operative physiotherapy late $[8,11,12]$.

Although there are studies investigating the effects of these parameters on the functional results and on the length of hospital stay in the literature $[15,16]$, there are no studies investigating the effects of the femoral stem length on inpatient functional results of hip arthroplasty and on early functional activities. In this study, we have determined that TPP, is a neck-sparing hip prosthesis, compatible with physiological loading has positive effects

both on the early-stage functional results of the hip joint and on the development of functional activities. Our data suggest that patients with TPP applications similar to short stems have significantly increased early stage functional results. Reason for this may include minimisation of bone and a soft tissue distribution with less vigorous. This will lead to earlier postoperative mobilisation and earlier discharge.

One of the goals of rehabilitation after conventional THP procedure is to help patients to become independent in the activities of daily living by gaining their functional levels as soon as possible. In this respect, evaluations are carried out to find out whether patients have gained the necessary functional levels during their hospital stay and after discharge [1]. A number of functional tests were considered for use (e.g. the Functional Independence Measure) [17,18,19]. The tests that comprise these outcome measures (e.g. cognitive function, sphincter control) seem more suited to patients undergoing longterm rehabilitation, rather than patients in the acute care setting [4,20]. In contrast, the ILAS assesses a range of functional activities that are representative of typical discharge criteria for conventional THP patients (i.e. ability to independently sit from lying, stand from sitting, walk and climb stairs). Furthermore, all components of the test are well described and a specific training manual for its use is available. Shields et al. [21] investigated the reliability, validity and responsiveness of the ILAS for 86 patients who had undergone total hip or knee replacement, assessing patients over the second to sixth post-operative days (approximately). They found that the ILAS was reliable (both intra-examiner and interexaminer reliability), valid (when compared with the Harris Hip Rating Scale) and sensitive to change over the study period, with a mean change of seven points for the total ILAS score found for their patient sample from the second to sixth postoperative day. Thus, the ILAS was chosen as the main outcome measurement for this study and, in our experience, was simple to use, reliable and sensitive to change over the study period [22].

Therefore, we used the IOWA scale to determine the early functional evaluations of the TPP and conventional THP patients in our study and found that TPP (though a 
cementless procedure) patients with full weight bearing had higher total functional scores than did conventional THP patients with full weight bearing and thus TPP patients were more functional than conventional THP patients when their early functional activities were compared. Table 5 shows that total ILAS scores varied both during the study period and between the two groups. In addition, it appears that total ILAS scores increased in the TPP group on the second and sixth postoperative days and during discharge compared with the conventional THP group.

When the reviewed the literature for the functional assessments of different conventional THP patient groups with the IOWA scale, Stokton et al. [23] found that ILAS score results in their study were higher than those in other similar studies were. They concluded end of their study weight bearing affects gait aid utilization, thus resulting in a higher ILAS score.

In our study too, TPP patients walked 13.4-meter distance in a shorter time than did the conventional THP patients (Table 5). Recent studies have been aimed to investigate the effects of conventional THP on walking velocity in different patients compared with healthy agematched groups [24,25]. A limited number of studies related to TPP that are available in the literature focus on the radiological and clinical outcome rather than walking velocity. Loizeau et al. [26] found the stance duration and gait velocity to be $0.70 \mathrm{~m} / \mathrm{s}$ on the operated side of patients with unilateral conventional THP and $0.95 \mathrm{~m} / \mathrm{s}$ in the healthy group. The same parameter was found to be $1.14 \mathrm{~m} / \mathrm{s}$ of both operated and non-operated sides in subjects with unilateral TPP, and $1.23 \mathrm{~m} / \mathrm{s}$ in healthy subjects. In our study, although both the conventional THP and the TPP patients were mobilized with early full weight bearing, we found that TPP application might improve early functional activities and walking velocity during the inpatient period following hip arthroplasty.

We think that although they both have similar weight transfer, TPP patients have better score development regarding their functional activity and walking velocity than do conventional THP patients, which may be due to the fact that TPP probably has higher physiological functional loading of the bone. We also consider that less traumatization of soft tissue resulting from better protection of bone stock in TPP applications will contribute to TPP patients' having better functional activities than conventional THP patients [1,9,27].

One of the most important targets following THP applications is to reduce the length of hospital stay. Prolonged length of hospital stay increases the chances of infection and the costs. In the literature, studies investigating the effects of the type and length of the incision and the length of femoral stem on the duration of hospital stay have found different results. Tahim et al. reported that short femoral stem applications significantly shortened the duration of hospitalization than did longstem femoral stem applications [9].

In other studies in the literature, hospitalization periods of patients with hip arthroplasty are reported to be 5 to 7 days [28]. In our study, there were no significant differences between hospitalization periods of conventional THP and TPP patients. However, the patients in our study stayed in the hospital longer than did the patients in the literature. We consider this might be due to the fact that in Turkey, patients with arthroplasty are not followed in a rehabilitation unit after discharge and that their rehabilitation programs are maintained in orthopaedic clinics.

The range of motion (ROM) of the hip joint, especially the ROM of hip flexion, can be directly associated with the basic activities of daily living (ADL), postoperative improvement in ROM of the hip is an important factor for restoration of ADL after conventional THP [29]. Patients with THP should regain ADL in proportion to recovery of hip function and range of motion. Early mobilization is the gold standard for achieving functional mobility, including sufficient range of motion after arthroplasty [30].

In conventional THP patients, hip range of motion is an important parameter to assess the in-hospital (early) results. Patients should have $50^{\circ}-60^{\circ}$ of hip flexion range of motion after conventional THP applications before they are discharged from the hospital, and that their active hip abduction should be between $25^{\circ}$ and $30^{\circ}$ [31]. Jesudason et al. [22] reported mean hip flexion as $43^{\circ}$ and hip abduction as $11^{\circ}$ at discharge. In our study, hip flexion and hip abduction in the patients with TPP were $57.1^{\circ}$ and $31.7^{\circ}$ respectively, whereas flexion and hip abduction in the conventional THP patients were $45.4^{\circ}$ and $23.4^{\circ}$ respectively (Table 6).

When we compared the range of hip flexion and abduction in the TPP and conventional THP patients at discharge, we found that the TPP patients have higher motion than the patients with conventional THP. In our study, the TPP patients achieved the targeted $50^{\circ}-60^{\circ}$ of active hip flexion and $25^{\circ}$ of active hip abduction before discharge. These results show that while TPP or conventional THP applications had an effect on the acquisition of range of motion, prosthesis type had an effect on improvements in hip flexion and abduction range of motion during inpatient rehabilitation. (or implant type had an effect on improvements in hip flexion and abduction range of motion during inpatient rehabilitation.) The data we obtained from our study revealed that TPP applications led to a significant difference in inpatient ROM findings (range of hip flexion and abduction) in terms of development ( $p<0.05$ ) (Table 6). We think that TPP patients' acquisition range of motion earlier might be due to the fact that TPP practices are probably more conservative, less invasive, that its placement is extramedullary, that less bone stock is used and that tissue trauma is less.

The number of the studies investigating early inpatient harris hip scores of TPP and conventional THP patients and the effects on the normal range of motion is limited $[8,32]$. Studies have usually evaluated 3- and 6-month, and 1 - and 5-year (medium-and long-term) function scores and the normal range of motion in TPP and conventional THP patients $[1,12,33,34]$. In our study, it was found that the patients with TPP achieved better functional levels than did the patients with conventional THP. The fact that TPP patients had better Harris hip score than conventional THP patients may have resulted from their certain advantages in the ILAS parameters and in the IAVS score. In study conducted on this topic by Shields et al. [21], they have pointed out the correlation between IAVS score and Harris hip score. One of the limitations of our study could be the fact that the relationship between IOWA parameters and Harris hip score was not studied.

These results indicate that femoral stem length has an effect on inpatient functional outcomes including HHS 
score, degree of hip motion (flexion and abduction), and early functional activities and walking speed following hip arthroplasty. These results will help physiotherapists and doctors to plan their inpatient rehabilitation programs and to provide effective usage of rehabilitation possibilities.

\section{Conflicts of Interest}

There are no any conflicts of interest regarding the submission and publication of the manuscript and its potential implications.

\section{References}

[1] Unver B, Karatosun V, Gunal I, Angin S (2004). Comparison of two different rehabilitation programmes for thrust plate prosthesis: a randomized controlled study. Clin Rehabil 18:84-91.

[2] Unver B, Karatosun V, Bakirhan S (2008). Effects of obesity on inpatient rehabilitation outcomes following total knee arthroplasty. Physiotherapy 94:198-203.

[3] Ganz SB, Wilson PD Jr, Cioppa-Mosca J, Peterson MGE (2003). The day of discharge after total hip arthroplasty and the achievement of rehabilitation functional milestones. J Arthroplasty 8:453-457.

[4] Karatosun V, Unver B, Gunal I (2008). Hip arthroplasty with the thrust plate prosthesis in patients of 65 years of age or older: 67 patients followed 2-7 years. Arch Orthop Trauma Surg 128:377381.

[5] Aarons H, Hall G, Hughes S, Salmon P (1996). Short-term recovery from hip and knee arthroplasty. J Bone Joint Surg $\mathrm{Br}$ 78:555-558.

[6] Bakirhan S, Unver B, Karatosun V (2009). Comparison of early postoperative functional activity levels of patients undergoing unilateral and bilateral total knee arthroplasty. Acta Orthop Traumatol Turc 43:478-483.

[7] Clark CR (1994). Cost containment: total joint implants. J Bone Joint Surg Am 76:799-800.

[8] Gocen Z, Sen A, Unver B, Karatosun V, Gunal I (2004). The effect of preoperative physiotherapy and education on the outcome of total hip replacement: a prospective randomized controlled trial. Clin Rehabil 18:353-358.

[9] Tahim AS, Stokes OM, Vedi V (2012). The effect of femoral stem length on duration of hospital stay. Hip Int 22:56-61.

[10] Berger RA, Sanders SA, Thill ES, Sporer SM, Della Valle C (2009). Newer anesthesia and rehabilitation protocols enable outpatient hip replacement in selected patients. Clin Orthop Relat Res 467:1424-1430.

[11] Rao RR, Sharkey PF, Hozack WJ, Eng K, Rothman RH (1998). Immediate weight bearing after cementless total hip arthroplasty. Clin Orthop 349:156-162.

[12] Karatosun V, Unver B, Gultekin A, Gunal I (2010). Thrust plate prosthesis for proximal femoral deformity: a series of 15 patients. Acta Orthop Traumatol Turc 44:437-442.

[13] Corner JA, Rawoot A, Parmar HV (2008). The thrust plate prosthesis in the treatment of osteoarthritis of the hip. Clinical and radiological outcome with minimum 5-year follow-up. Hip Int 18:88-94.

[14] Unver B, Karatosun V, Gunal I (2005). Assessing the results of thrust plate prosthesis: a comparison of four different rating systems. Clin Rehabil 19:654-658.

[15] Huddleston JI, Wang Y, Uquillas C, Herndon JH, Maloney WJ (2012). Age and Obesity Are Risk Factors for Adverse Events After Total Hip Arthroplasty. Clin Orthop Relat Res 470:490-496.
[16] Kinkel S, Wollmerstedt N, Kleinhans JA, Hendrich C, Heisel C (2009). Patient activity after total hip arthroplasty declines with advancing age. Clin Orthop Relat Res 467:2053-2058.

[17] Johanson MA, Cohen BA, Snyder KH, McKinley AJ, Scott ML (2009). Outcomes for aging adults following total hip arthroplasty in an acute rehabilitation facility versus a subacute rehabilitation facility: a pilot study. J Geriatr Phys Ther 32:73-78.

[18] Mallinson TR, Bateman J, Tseng HY, Manheim L, Almagor O, Deutsch A, Heinemann AW (2011). A comparison of discharge functional status after rehabilitation in skilled nursing, home health, and medical rehabilitation settings for patients after lowerextremity joint replacement surgery. Arch Phys Med Rehabil 92:712-720.

[19] Dejong G, Horn SD, Smout RJ, Tian W, Putman K, Gassaway J (2009). Joint replacement rehabilitation outcomes on discharge from skilled nursing facilities and inpatient rehabilitation facilities. Arch Phys Med Rehabil 90:1284-1296.

[20] Zavadak KH, Gibson KR, Whitley DM, Britz P, Kwoh CK (1995). Variability in the attainment of functional milestones during the acute care admission after total joint replacement. J Rheumatol 22:482-487.

[21] Shields RK, Enloe LJ, Evans RE, Smith KB, Steckel SD (1995). Reliability, validity, and responsiveness of functional tests in patients with total joint replacement. Phys Ther 75:169-179.

[22] Jesudason C, Stiller K (2002). Are bed exercises necessary following hip arthroplasty? Aust J Physiother 48:73-81.

[23] Stockton KA, Mengersen KA (2009). Effect of multiple physiotherapy sessions on functional outcomes in the initial postoperative period after primary total hip replacement: a randomized controlled trial. Arch Phys Med Rehabil 90:16521657.

[24] McCrory JL, White SC, Lifeso RM (2001). Vertical ground reaction forces: objective measures of gait following hip arthroplasty. Gait Posture 14:104-109.

[25] Perron M, Malouin F, MoVet H, McFadyen BJ (2000). Threedimensional gait analysis in women with a total hip arthroplasty. Clin Biomech (Bristol, Avon) 15:504-515.

[26] Loizeau J, Allard P, Duhaime M, Landjerit B (1995). Bilateral gait patterns in subjects fitted with a total hip prosthesis. Arch Phys Med Rehabil 76:552-557.

[27] Karatosun V, Unver B, Gultekin A, Gunal I (2011). A biomechanical comparison of the thrust plate prosthesis and a stemmed prosthesis. Hip Int 21:565-570.

[28] Munin MC, Hockenberry PS, Flynn PG, Toplak W (1998). Rehabilitation. In: Callaghan JJ, Rosenberg AG, Rubash HE, editors. The adult hip. Philadelphia: Lippincott-Raven 1571-1579.

[29] Yoshii T, Jinno T, Morita S, Koga D, Matsubara M, Okawa A, Sninomiyak A (2009). Postoperative hip motion and functional recovery after simultaneous bilateral total hip arthroplasty for bilateral osteoarthritis. J Orthop Sci 14:161-166.

[30] Nankaku M, Tsuboyama T, Kakinoki R, Akiyama H, Nakamura T (2011). Prediction of ambulation ability following total hip arthroplasty. J Orthop Sci 16:359-363.

[31] Efthekhar NS (1993). Total Hip Arthroplasty. Missouri: Mosby.

[32] Ferrara PE, Rabini A, Maggi L, Piazzini DB, Logroscino G, Magliocchetti G, Amabile E, Tancredi G, Aulisa AG, Padua L, Aprile I, Bertolini C (2008). Effect of pre-operative physiotherapy in patients with end-stage osteoarthritis undergoing hip arthroplasty. Clin Rehabil 22:977-986.

[33] Angin S, Karatosun V, Unver B, Gunal I (2007). Gait assessment in patients with thrust plate prosthesis and intramedullary stemmed prosthesis implanted to each hip. Arch Orthop Trauma Surg 2:91-96.

[34] Fink B, Siegmüller C, Schneider T, Conrad S, Schmielau G, Rüther W (2000). Short-and medium-term results of the thrust plate prosthesis in patients with polyarthritis. Arch Orthop Trauma Surg 120:294-298. 